\title{
The Design Aesthetics of Lacquerware in the Han Dynasty
}

\author{
Dalei Chen \\ Art Department of Henan Institute of Education \\ Zhengzhou, Henan, 450000
}

\begin{abstract}
China is a large country with a long history. It is reputed as the "Silk Producer", "Porcelain Country", and also famously known for the lacquerware. China has a long history of the making of lacquerware. Ancient China is the earliest and largest country that use lacquerware as daily ware. In the Han Dynasty, the making and using of lacquerware has reached its peak. As the crystallization of human mind and the product of culture, lacquerware not only represented the culture of a particular time, but also embodied the creators' understanding of the particular culture. The design aesthetics formed on the basis of Han Dynasty culture embodied various category from functional aesthetics to symbolism.
\end{abstract}

Keywords-Han Dynasty lacquerware, design aesthetics, design theory

\section{ROLE OF THE HAN DYNASTY LACQUERWARE IN CHINESE HISTORY}

China has the largest number of unearthed lacquerware objects, and the places of relics can be found throughout China. The lacquerware unearthed could be found in many places, from the Pearl River area to the Yangtze River area, from the Huaihe River area to the Yellow River area. It is evident that lacquerware was widely used in ancient China.

From the wooden lacquerware unearthed in Hemudu cultural relics, the history of utilizing ancient Chinese lacquerware could be traced back to 4,000 years ago, at the end of the Neolithic Age. It was during that time that the lacquerware came in use. From the Pre-Qin period till today, lacquerware has always taken an important part in people's life, and has reached its prime period in the Han Dynasty, Song Dynasty and Ming Dynasty. The making of lacquerware embodied the particular cultural background of a certain period, and thus formed the particular design aesthetics. Even though there would be slight change from functionalism to decorationism, people's love for lacquerware never has changed. During the Han Dynasty, the using and making of lacquerware have reached a peak. It is because of the beauty of the lacquerware itself and the function of the lacquerware in the particular period that made lacquerware reach its prime period in certain period.

\section{Cultural CONNOTATiOn OF THE HAN DyNASTY LACQUERWARE}

There is wide cultural background of the beginning and development of the design of the Han Dynasty Lacquerware. The design theory of the Han Dynasty lacquerware inherited a lot and carried forward the system of the Qin Dynasty and the culture of Chu.

The Han Dynasty has inherited the Qin Dynasty's political system in some aspects, which have given some inspiration to the design theory of lacquerware. The design theory of the Han Dynasty is an all-embracing one. Until the reform of the Emperor Han Wudi, the Qin and Chu culture has been fully blended with the design culture of the Han Dynasty. The design theory is represented on the management rule of the design in the fist place. It is said that in the Qin Dynasty, the standard of weights and measures were unified. People should write by using the same kind of characters and the space between the two wheels of a coach should also be the same ${ }^{1}$. In the Han Dynasty, compulsory management was performed by the government on the management of the lacquerware design system. Since the Qin Dynasty has lasted for a short period, only 20 years, thus the theory of writing same kind of characters and keep same space between the two wheels of a coach haven't really extensively employed at that time. It was in the Han Dynasty that this kind of standard design theory was realized and represented in the designing of the lacquerware indeed. Secondly, in the Qin Dynasty, black was widely used in the design of lacquerware. This principle was also represented on the color of the Han Dynasty lacquerware. In the Qin Dynasty, people took black as the noble color, as well as the most expensive color. Black stands for the moral character. As one kind of utensils used by the upper class of the society, lacquerware has to represent the social status of the ones who use. Thus, the lacquerware has the function of symbolism. On the other side, the lacquerware was also inherited from cultural custom of the Qin Dynasty. There was a large amount of Qin Dynasty style lacquerware used in the Han Dynasty. In the process of the excavation of the Jiangling Chu Tomb in the Western Han Dynasty, Mr. Guo Dewei has said that in the early period of the Western Han Dynasty, the display, making and design of the lacquerware mostly adopted from the tradition of the Qin Dynasty after serious study ${ }^{2}$. From this aspect, it was obvious that the design theory of the Han Dynasty lacquerware was deeply influenced by the Qin Dynasty. 
According to the thinking of Laozi and Confucius, in order to rest and build up its strength and promote the steady economic development, the Emperor Han Wudi has adopted the policies of recuperate and multiply. As reflected on the design theory, frugality was advocate in this period, which also fits the doctrine of Lao $\mathrm{Zi}$ that advocate frugality and against extravagant in the beginning of the Han Dynasty. According to Lu Jia, the downfall of the Qin Dynasty is the result of the extravagant and dissipated life style of the emperor: the governor was indulged in building luxury palaces, and then the rich people all follow the governor's practices. At that time people were found of carving and painting, and indulged in Taoism, therefore, the society was collapsed. ${ }^{3}$ Emperor Han Wudi earnest practice what he advocated and built his tomb--Ba Ling by himself, thus exerted a great influence on the ruling class. Even though the making of lacquerware was time and effort consuming, lacquerware still played a very important role in the daily life mainly because the making of porcelain haven't been fully developed at that time. Lacquerware was the necessity of daily life, not goods that being banned. As an industrious emperor, Han Jingdi has also performed some economical behavior, such as farming and rising silkworm by himself. According to Han Shu Jingdi Ji, it was recorded that in summer, April, the Emperor said that carving is harmful to farming, and luxurious embroidery work is harmful to needlework. Bad farming will result in hungry of the people, while bad needle work will cause people could not wear warm. When hungry and could came together, it is the end of a dynasty. ${ }^{4}$ He believed that excessive decoration would be harmful for the development of agriculture. This concept was reflected on the art design theory at the beginning of the Han Dynasty. The practice of advocate frugality at the beginning of the Han Dynasty have some influence on the restraining of the prevailing luxury burial in the Qin Dynasty. On the design of the lacquerware, luxury decoration could not suit people's needs and taste at that time.

Confucianism began in the Spring and Autumn Period, and was developed during the Warring States Period. During the reign of the Emperor Han Wudi, as advocated by Dong Zhongshu, Confucianism has been taken as the orthodox state ideology because Confucianism has the nature of serving for the imperial power. This has also influenced the design theory of the middle and later period of the Han Dynasty. On the designing of lacquerware, the strict hierarchy concept based on courtesy advocated by the Confucianism was reflected, especially on the amount and social status of funeral utensils. The coffins of the emperor were coated with black lacquer, which was called red through both outside and inside of the coffin. The coffins of the noble families were painted black outside and red inside. This could reflect the differences between the emperor and the noble family.

In the Preface of Shi Ji Ru Lin Wai Zhuan, it is recorded that the Han Dynasty became prosperous. The disciples of Confucianism could learn and practice its doctrines. There were more and more learned people follow the doctrines of Confucianism. In order to suit for the teachings of Confucianism, the design of the utensils in the Han Dynasty all reflected Confucianism, no exception for the making of lacquerware.
The development of Chen Wei Theology: Lu Tu Shu written by Lu Sheng was the beginning of Chen Wei Theology. During the reign of Qin Shihuang 32 year, Lu Sheng, from Yan, came to Hai Huan, and did things related to gods and ghosts. He made a prophecy in the Lu Tu Shu saying, Hu is the one who end the Qin Dynasty. ${ }^{5}$ At the end of the Qin Dynasty, the leaders of civil revolts also employed gods and ghost to call for the peasant people by making a prophecy. As recorded in Shi Ji Chen She Shi Jia, Chen Sheng said that people have been badly ruled by the Qin Dynasty for a long time. At present, if we pretended to be Prince Fu Su, Xiang Yan, and called for the people, I believed there will be a lot of followers. $\mathrm{Wu}$ Guang agreed with him, and then went to the fortuneteller. The one who practiced divination knew what they want and told them they will be succeed at the things they were going to do. Chen Sheng and Wu Guang were happy, and said, "I need to first make people believe me."Then he wrote in the silk "Chen Sheng is the Emperor" and put the silk in the stomach of fish. Soldiers bought the fish and cooked it, then got the silk in the stomach, feeling weird. Then, they also heard at night in many places, a voice like fox saying that Chen Sheng will be the Emperor of Chu. They were all very scared. In the morning, they began to say to each other about what happened and looking for Chen Sheng to be the leader.

According to the analysis, the word"Chen"(meaning prophecy) was pure fabricated by some supernatural beings in order to meet people's needs. It is indeed superstitious. Even though those superstitious gods and ghosts were fabricated because of the underdeveloped science technology, which cannot explain the phenomenon in the whole universe, they were the most inspiring and provocative sayings. Therefore, when Liu Bang, the Emperor Han Gaozu led the revolt, he employed the same manner.

From the middle Western Han Dynasty, things became different. As long as the establishment of the role of Confucianism in the society and Confucianism was regarded as the sacred doctrine, "Chen"(meaning prophecy) was mixed together with Confucianism gradually. On the one hand, Confucianism needs the support of superstitious gods and ghosts to reinforce the ruling of the feudalism royal family; on the other hand, "Chen"(meaning prophecy) needs the help of Confucianism to enlarge its scope of knowing. Therefore, these two schools mixed together gradually, and thus came up with the "Chen Wei"theology.

Chen Wei Theology and the doctrine of go to heaven to become immortal have great influence on the design theory of the lacquerware at that time. Theology was transformed into decoration patterns, and the decoration was used in the ornament of the lacquerware. This trend of design could be connected with the prevailing of the luxury funeral at the middle and end of the Han Dynasty. The images of gods and fairy things could be found everywhere, such as Fuxi, Nuwa and fairy mountains, etc.

Under such background, the culture and ideology of this time have some influence on the literature and art, as well as the design culture. Thus formed the particular design aesthetics. 


\section{THE SPECIFIC EXPRESSIONS OF THE DESIGN}

\section{AEsthetics BASED on FunCTIONALISM AND SyMbOLISM}

Design aesthetics is a kind of creation philosophy, the principle the designer need to abide by when design the products. It contains different levels of contents from human utilitarian function to the symbolism on the spiritual level. If one needs to discover the design aesthetics of lacquerware, one must consider the lacquerware under the background of the whole historical culture. This is also because every designer was lived in the particular period and was influenced by politics, economy, culture, religion and tradition of the particular period, and thus formed his own design aesthetics theory.

The basic principle of design is to create true, good and beautiful things, and endow the goods with added value. These design aesthetics theories were well represented in the design theory of Han Dynasty lacquerware.

From the angle of design aesthetics, the making techniques of Han Dynasty lacquerware were the combination of function and beauty, containing both romanticism and the concept of distinguish one thing from another. These concepts were reflected on the molding, patterns, decoration and techniques and so on in the making of the lacquerware. On the other hand, the lacquerware designer himself's special understanding of creation culture also greatly promoted the development of the making of Han Dynasty lacquerware.

\section{A. The making of Han Dynasty lacquerware---Beauty of the techniques}

The design of the product is highly dependent on technology, therefore, the product could be made and finished. The development of handicraft techniques in the Han Dynasty has provided a lot of possibilities for the designing of lacquerware. In the converse, technique of the making of lacquerware plays an important role in the creation of lacquerware.

The handicraft industry was well developed and was divided into two types: official owned and privately owned. The making of lacquerware has some similarities with the making of bronze and pottery vessels, as well as silk weaving: they are the important element of highly developed official owned handicraft industry. Lacquerware making also has been owned privately. Especially in the Eastern Han Dynasty, manorial economy was developed. A landlord's mansion could be regarded as a single unit of social production, which could produce almost all the handicraft objects people need. Han Shu Zhang Tang Zhuan said that: An Shi was the noble family, with a fief of 10,000 families. However, he wore the coarsely woven black cloth and his wife did the spinning herself. He has over 700 family servants, and each of them has his own handicraft and did his own work. He accumulated his belongings form the very tiny things and thus has a large amount of property. He was richer than the general Huo Guang. From this description, we can see that as an important part of the handicrafts of the Han Dynasty, lacquerware was highly dependent on the development of the privately owned handicraft industry, operating by the castrated families.

\section{B. Techniques of Han Dynasty lacquerware}

The techniques of the Han Dynasty lacquerware were mainly reflected on the bodies and painting of the utensils. Those two aspects were considered based on the proper property and the special function of the lacquerware. The body of the lacquerware was always made of wood and paints, some of them were also made of bamboo. There are three kinds of ways of making the wooden body: wheel rotation, cutting and digging, and rolling. Different kinds of body would employ different manner of making. The ways of Jia Tai was also known as bodiless paints. First, using wood or clay to make the mold as the internal model, and then place several layers of linen cloth or silk around the internal model, then paint each layers. After they were dried, remove the internal model, and only left the body made of linen cloth or silk.

\section{Connotation of the lacquerware's decoration---Beauty of decoration}

In different period of the Han Dynasty, there were different schools of Xian Xue ( Learning), such as theory of Lao Zi and theory of Han Confucianism. There schools of thinking were reflected in the pattern designing in the decoration of the lacquerware. The decoration patterns in the Han Dynasty contained the thinking of Taoism, which advocated a kind of thinking beyond the subject of space and limitation. According to Taoism, the dimension of space and time are limitless. The Taoism's thinking on space has various influences on the art design in the Han Dynasty both on the decoration and on the drawing. As reflected on the decoration aesthetics of the designing of lacquerware, the most prominent thing was that there were a lot of ever-changing patterns of the mists. Curves and $\mathrm{S}$ lines all represented the infinite dimension of space; however, there is a kind of balance in the infinite. According to Taoism natural concept of space, things in the universe interchange regularly, just like the flowing clouds and never collapse. This is the beauty of nature. Huai Nan Zi Shuo Shan Xun said that: when you seek the beauty hard, you may not get the real beauty; when you do not seek the beauty hard, you may easily get the real beauty; when you seek the ugly thing hard, you may not get; when you do not seek the ugly thing hard, you may get it. ${ }^{6}$ Romanticism was also fully represented in the decoration patterns of the lacquerware.

\section{Manner of decoration of the Han Dynasty lacquerware}

Lacquer painting, oil paints, pasting gold and silver foils, and piling lacquer. Lacquer painting was very commonly used in the decoration of Han Dynasty lacquerware: making raw lacquer into semitransparent liquid lacquer, adding all kinds of colors into the lacquer and then paint on the utensils that have already lacquered. The color was clear and bright, and was not easy to be detached. Most patterns on the lacquerware were painted by this manner. Oil painting means mix oil (probably Tung oil) with different color and then drawn on the lacquered vessels. Since the oil could be aging, so the patterns painted could be easily fall off. Line carving mainly refers to use needle to carve patterns on the lacquered utensils. Sometimes, people add gold color into the gap carved by the needle, thus it may seems as the patterns were painted with gold and silver. Pasting gold and silver foils means make different kinds of 
patterns by using gold and silver foils and paste them on the surface of the vessels. This made the lacquerware looks detailed and fluent. Piling lacquer: Patterns on the Coffin of the Western Han Dynasty unearthed in Changsha were all made by piling thick lacquer. The swirling pattern on the jade bi and the sidelines of the patterns were all made by special techniques by using thick colors. Usually higher a little to make it seems like relief. "Shi Wen Yin Qi" is a kind of this technique. This is an unprecedented discovery. Piling lacquer employed by Chinese people two thousands years ago showed that the lacquerware making techniques were highly developed in the Han Dynasty. Embedment: after the mid Western Han Dynasty, it was popular to embed gilding or silvering hoops on the edge of the plates, vessels, boxes and mirror cases and so on. Utensil embedded with gilding cooper shell on the ears was call silver mouth and gold ears. There were always gilding copper decorations on some lacquerware, such as vessels, mirror cases and the covers of the boxes. Sometimes there were even crystals and glass beads.

\section{E. Patterns and color of Han Dynasty lacquerware}

Patterns on the lacquerware in the Han Dynasty were mainly flowing clouds, whirling pattern, Pan Li pattern, diamond-type lattice pattern and birds and beasts. The colors were mainly red and black, or red with green, or red with gold, bright and graceful. Portrait painting always employed the subject of the stories of dutiful sons and fairy characters. Sometimes there were also painted with fairy and eagle, adding some birds or beast flying or running in the flowing clouds. The line of the painting was flowing smoothly. This subject shares similarities with the subjects in the tomb, fresco, relief brick sculptures and so on. They all reflected people's willing to go to heaven and became fairy characters. Patterns on the lacquerware in the early period of the Western Han Dynasty were sumptuous and complicated, however, pattern on the lacquerware in the Eastern Han Dynasty were simple and elegant. From the middle Western Han Dynasty to the Eastern Han Dynasty, only few of the lacquerware were painted with fairy character, dutiful son and other figures.

\section{F. Beauty of the modeling-Variety of the model of Han Dynasty lacquerware}

In order to meet the needs of daily life, from the angle of functional aesthetics, the model and size of the Han Dynasty lacquerware were various. Human factors engineering was also reflected in the making of lacquerware in the Han Dynasty. The design aesthetics represented by the lacquerware contained people's felling. As long as people's life styles changed, the new style of lacquerware came into being.

From the angle of functionalism, there were various kinds of lacquerware, mainly utensils used for dinning and drinking. The lacquering utensils including dinning utensils such as ding, pot, vessel, spittoon, cup, plate, etc., dressing things such as mirror cases, boxes, etc., and furniture such as tea table, long table, screen and so on. Compared with the Warring States Period, there were many new types and the number of lacquerware also rose in a large amount. Meanwhile, there were large type of lacquerware, such as ding and pot, etc.. There were also ceremonial utensils to replace bronze vessels.
In the tombs of the Han Dynasty, there were also lacquering coffin, bowl, plate, long table and cup and so on.

\section{G. Symbolism---The cultural connotation of lacquerware}

The trend of luxury burial directly promoted the development of lacquerware in the Han Dynasty. As the carrier of the design of lacquerware, the making techniques also got fully development at that time. The making of lacquerware was time and effort consuming, however, behind this was the symbolic design aesthetics of the designer. Huan Kuan in the Han Dynasty wrote in Yan Tie Lun, making a drinking vessel needs the efforts of a hundred people, and making a screen needs the efforts of ten thousands of people. This shows that the making procedures of Han Dynasty lacquerware were extremely complicated. It was mainly because of the complication that lacquerware were mainly used by the families of the upper class, and seldom by the ordinary people. Lacquerware has become a symbol of social status.

Along with social development and the rising of people's live standards, lacquerware has become a luxurious good in the upper class, and more valuable than bronze utensils. As is recorded in Yan Tie Lun $\mathrm{San} \mathrm{Bu} \mathrm{Zu}$, the rich people use lacquerware (silver mouth and gold ears utensils), the middle class use Jin Cuo Shu cup, while the lower class use the bronze cup which cost only a few money.

The came into being of a complete set of lacquerware reflected a principle of design aesthetics theory, that is people's needs changed from inadequate to adequate. The social status and function of lacquerware can be traced back to Han Fei Zi Shi Guo: I have heard that when the Emperor Yao ruled the world, he used Gui to eat and Zha to drink. The area of the country reached to Jiaozhi ( Vietnam now) in the south and Youdu (Beijing now) in the north, where sun and moon start and rest in the east and west. After Emperor Yao, there is the Emperor Yu and Shun. They made the people cut trees and carved on the wood, lacquered on them and send to the royal palace, so they have the utensils to eat and drink.

\section{CONCLUSION}

Confucianism, Taoism, Chen Wei Theology, Qin and Chu Culture in the culture of the Han Dynasty composed the design theory of lacquerware. These schools of thinking also transformed into patterns and became the important elements of the design of lacquerware in the Han Dynasty.

\section{REFERENCES}

[1] Southern Dynasty Song, Fan Ye, Hou Han Shu Li Yi Zhi, China Publishing Company punctuated edition, 1965

[2] Western Han Dynasty, Sima Qian, Shi Ji Qin Shi Huang Ben Ji, the six part, China Publishing Company punctuated edition, 1959

[3] Guo Weide, Considering the Relationship Among the System of the Qin Dynasty, Chu and The Han Dynasty. P.245. Chu Shi Lun Cong, People's Publication Company of Hubei. 1984.

[4] Western Han Dynasty, Lu Jia, Xin Yu Wu Wei

[5] Eastern Han Dynasty, Ban Gu, Han Shu Jing Di Ji, China Publishing Company punctuated edition, 1962 
[6] Western Han Dynasty, Sima Qian, Shi Ji Qin Ben Ji. China Publishing Company punctuated edition, 1959

[7] Han Dynasty, Liu An, Huai Nan Zi Shuo Shan Xun. China Publishing Company punctuated edition, 1959

[8] Zhuge Kai, Techniques of Ancient China Lacquerware.

[9] Hang Jian, History of Chinese Crafts and Aesthetics, Bei Yue Publishing Company.

[10] Li Yanzu, Dimension of Design, Chongqing University Publishing Company, 2007.

[11] Li Yanzu, The Beauty of Making Utensils: Art and Culture of Designing.

[12] Liu An, Han Dynasty, Huai Nan Zi, China Publishing Company,1959.

[13] Sima Qian, Western Han Dynasty, Shi Ji, China Publishing Company, 1959.

[14] Guo Weide, Considering the Relationship Among the System of the Qin Dynasty, Chu and The Han Dynasty, People's Publication Company of Hubei, 1984.

[15] Lu Jia, Western Han Dynasty, Xin Yu.

[16] Ban Gu, Eastern Han Dynasty, Han Shu China Publishing Company, 1962.

[17] Fan Ye, Southern Dynasty Song, Hou Han Shu, China Publishing Company, 1965.

[18] Xiu Shi Lu.

[19] Wang Shixiang, Explanation of Xiu Shi Lu.

[20] Cao Lin, the Tradition of Chinese Decoration and its Cultural Value, Doctor's Thesis of China Art Institute, 2005.

[21] Xu Dahai, Design Theory of Art in the Han Dynasty, Doctor's Thesis of Suzhou University, 2005. 